\title{
The Relationship between GDP and Unemployment Rate in the U.S.
}

\author{
Dr. Claudius Mandel \\ University of Cologne, Professional Center \\ FOM - Hochschule für Oekonomie und Management \\ Germany \\ Peter Liebens \\ University of Applied Sciences (TH Köln) \\ Germany
}

\begin{abstract}
Gross Domestic Product (GDP) and unemployment rate are two key figures to determine a country's degree of prosperity. High unemployment rate shows that the labor availability is not used efficiently. This paper observes the correlation between the Gross Domestic Product and the unemployment rate in the U.S. - over a long period of time, i.e. 50 years. By using an econometric model we run multiple regression analysis to test our hypothesis that is that a decreasing GDP rate through slow economic growth leads to an increasing unemployment rate. Supported by a review of relevant literature we discover a continuously existing negative correlation between the GDP and the unemployment in the U.S. over the last fifty years.
\end{abstract}

Keywords: Gross Domestic Product, unemployment rate, U.S.

\section{Introduction}

The objective of our paper is to discuss and analyze the possible correlations and causalities between the Gross Domestic Product (GDP) and the unemployment rate in the U.S. in the last 50 years. The topic of unemployment is very important and highly discussed in every country. A high unemployment rate means that a lot of people are living at the breadline and a high percentage of these people will live below the breadline in the future. From an economic perspective, a high unemployment rate shows that the labor availability is not used efficiently. Thus, full employment should be one of the most important goals of every country. In our paper, we want to analyze and discover all the future outcomes of this correlation and predict what will happen to the rates going forward. Our general hypothesis is that a decreasing GDP rate through slow economic growth should lead to an increasing unemployment rate. Reduce in consumer spending is the key problem that countries have: if the consumer spending stays small and high unemployment continues, this could lead to a recession or in worst case to a depression scenario. Thus, it is a major assignment for us to have a precise look at the relationship between GDP and unemployment rate (over a long time). Not a long time ago countries around the globe got into a huge economic catastrophe as the Financial Crises beginning August 2007 terrified the world. This crisis originated as a huge bubble formed in the housing markets. The consequences were enormous: millions of Americans lost their homes, banks were closing, and an immense number of people all over the globe lost their jobs. In 2017 Barack Obama was replaced and with the new President Trump on board, GDP and the unemployment rate were thought to hypothetically significantly change in the nearest future. For real GDP and unemployment rate the website of Bureau of Economic Analysis is the source we will get our data from. In addition to real GDP and unemployment rate, we include the industrial production index (INDPRO), the Consumer Price Index (CPI), and the annual personal income into our model. For INDRO and CPI we get our data from the Federal Reserve Database and for personal income we get the data from the website of Bureau of Economic Analysis. We use an econometric model to estimate the impact the before listed variables have on the unemployment rate. All in all, our hypothesis is that if GDP decreases, unemployment rate will increase. Therefore, we assume that we have a negative correlation between the two variables that we look at over a long period of time, namely fifty years.

\section{Review of Literature}

We will discover the correlation between the GDP and the unemployment rate. We already mentioned how important it is for the people around the world and how many are influenced by this correlation. There were multiple research papers found that were relevant to the selected topic. The first paper "Effects of debt and GDP on the unemployment rate: an empirical study" (2015) by Morsheda Hassan and Raja Nassar talks about the fundamental importance of debt and GDP and their effects on the unemployment rate of a country. 
Their diverse knowledge is a great benefit for the readers of this paper as it applies multiple areas to the researched topic. Authors of this paper were using the debt ratio data in order to find a correlation between debt percentage in the different countries and GDP. This helped them to better analyze the correlation between unemployment rate and GDP. Results of this paper showed that GDP has a negative correlation with debt and with unemployment rate. It was also concluded that deficit on unemployment was a result of the GDP's negative effect (deficit). As in this paper, authors agreed that among all economic variables that have high impact on the unemployment rate, GDP is probably the most important. Authors highlighted that when unemployment is down-sloping, unemployment is rising because of the slowdown in hiring and layoffs by industries around the country. They used time series methodology in order to investigate the correlation and build series models that relate unemployment to GDP and debt using the data from different countries, including the United States. This paper is very interesting because by using different countries data authors were able to apply different mix of economies, from small to large, and some even had their own central banks while other countries didn't. Also, application of the different monetary and fiscal policies helps to apply data more effectively. This paper is relevant to our topic as it talks about the effects on GDP on the unemployment rate in different countries, including the United States. Data and results provided in this paper signifying that our hypotheses are correct and the negative correlation between the GDP and the unemployment rate does exist.

Paper "A Multiple Regression Analysis Fiscal Strategies and Unemployment Rates" by Richard Carter (2014) talks on how full employment levels may be sustained by various means of fiscal stimulus spending. In this paper data from the infrastructure spending, defense spending, net government budget spending, gross private domestic investment (GPI), consumer price index (CPI), money supply (M2) and a refines measure of defense spending with unemployment were used in order to analyse influence on the unemployment rate. He is applying Keynesian approach to gain more significant areas that can be a help to analyze fiscal strategies and unemployment rates. Dr. Carter applying statistical regression analysis to determine the confidence levels that he then translates into the goodness of fit that then helps to predict the position of the unemployment rate. In our paper, we are also using consumer price index (CPI), personal income and industrial production index (INDRO) in order to analyse the correlation between the GDP and the unemployment rate. Besides that, he is testing for normality, lack of feedback for the dependent variable, data collection errors, multicollinearity and outliers in his paper. Instead of STATA he is using StatPlus to generate a correlation matrix to present variance inflation factor (VIF) in order to measure for the independent variables. Along with this, Dublin-Watson test is being used. We will follow similar steps to get results for our paper, but instead of Dublin-Watson test, we will use Breusch-Pagan Test that should be better fit for our model.

Paper "Economic development and the level of unemployment in the conditions of economic recession" by SergejVojitovich(2011) is talking about GDP growth before the recent economic crisis. In his paper Vojitovich discovered that relationship was not very clear and that other factors might be in place like industry confidence. His paper is relevant to our topic as he is explaining correlation and influence of the economic crisis on the unemployment and uses statistic data to conduct that there is no expected tight indirect correlation between GDP height and unemployment rate.

In paper "Analyzing the link between real GDP and employment: An industry sector approach" (2007) the author uses regression analysis on data in the US between 1991 and 2001 showing controlling for macro variables and considering unemployment by industrial sector is important when determining the relationship between GDP and unemployment. This paper has direct connection with our paper as the author talks about the "jobless recovery" phenomenon that U.S.has recently experienced. Even though the author is talking about 1991-2001 years and they are not within the range we are researching it is a great way to understand correlation between GDP and unemployment rate in the past as it is directly reflected on the following years that we are trying to highlight. In the paper the author was using monthly data and OLSQ regression that helped to derive industry-sector elasticity of unemployment with respect to real GDP and she used White test as one of her tests for heteroscedasticity, Breusch-Godfrey test, and Augmented Dickey-Fuller test were applied to the scaled equation estimates. These tests suggested the presence of serial correlation of the residuals in all equations, uncorrected heteroscedasticity in many, and unit roots in the scaled construction employment and scaled employment cost index variables. Results showed that negative employment elasticity is in place and that it's really influenced "jobless recovery".

Paper "Unemployment in the Great Recession: A Comparison of Germany, Canada, and the United States" by Florian Hoffmann and Thomas Lemieux (2015) helped us to understand how unemployment has changed during the great recession, which was between December 2007 - June 2009. They addressed their question by comparing different countries unemployment rates and behaviors during the same period of time - Great Recession. 
In their paper, they contrasted the experience of the United States to the experiences of a large set of OECD(Organization for Economic Cooperation and Development) countries using aggregate labor market data and various other standard economic indicators, then they conducted a detailed analysis using rich micro data for the United States and two comparison countries - Canada and Germany. Overall, they were exploring all possible explanations for the weak labor market performance of the United States and compare it with the same period market performances of the comparison countries. They concluded that their international comparison suggests that industrial composition is strongly associated with the labor market impact of the Great Recession and that countries, states and provinces with a pre-crisis construction boom were particularly severely hit by the Great Recession crisis. Also, countries whose output decline was mainly driven by a decline in exports ended much better.

\section{Data}

In our multiple regression analysis, the unemployment rate (in \%) is $\mathrm{Y}$, which is also the dependent variable of the regression analysis. Our X (independent variable) is the real GDP Index. After the establishment of our variables, we integrated the independent control variables: INDRO, CPI, and personal income. We obtained all the data for the period of 50 years (from 1967to 2016) and divided it into quarters; therefore, our number of observations is equal to 50x4=40, $\mathrm{n}=200$. We utilized The Federal Reserve Database website as our source for GDP, unemployment rate, CPI, and INDRO, and the Bureau of Economic Analysis website as a source for personal income. We also will use the dummy variables in order to improve our model. The descriptive statistics for the data we chose are shown in the Figure 1 from STATA. The reasons for choosing and including the independent control variables INDRO, CPI, and personal income are simple: high unemployment rates are mostly caused by slow economic growth. This fact is measured by GDP. When GDP decreases, companies release (fire) their workers and, as a result, there are no new hires anymore. Unemployed workers spending power is significantly decreasing up until they find a new job. Since consumers stop spending, businesses' revenues decrease, and, as a consequence, industrial production index decreases. Companies reduce waged paid to the workers in order to save costs, so the personal income decrease. This downward trend in economy can go very quickly. If a country gets into a recession or even a depression, the prices will go down and the government would want the people to invest in the economy. Government will try to stimulate economic growth again by making people buy. Thus, the interest rates will decline that will produce low inflation during that period of time.

\section{Methodology and Results}

For our multiple regression analysis, we first tried to explain unemployment rate by GDP, INDRO, CPI, and personal income in the U.S. in the last 50 years. The number of observations is 200. Our final regression function follows:

Legend:

$$
\begin{gathered}
U_{t}=B_{1}+B_{2} U_{t-2}+B_{3} G D P_{t}+B_{4} G D P_{t-1}+B_{5} I N D R O_{t-1}+B_{6} I N D R O_{t}+B_{7} C P I_{t-1}+B_{8} C P I_{t}+B_{9} P_{t} \\
+B_{10} P_{t-1}+B_{11} \text { Break }_{t}+u_{t}
\end{gathered}
$$

$U_{t}$ is the unemployment rate,

$G D P_{t}$ isthe real GDP Index,

$I N D R O_{t}$ is the Industrial Production Index seasonally adjusted,

$C P I_{t}$ isthe real Consumer Price Index seasonally adjusted,

$P I_{t}$ isthe Personal Income per capital seasonally adjusted,

Break $_{t}$ is the Break,

$u_{t}$ represents the error term.

In our model, we deal with the time series that involves quarterly data. We received our data by adding the monthly observations and dividing the result by three, because of this averaging there is a "smoothness" in our data by dampening the fluctuations in the monthly data. This introduces autocorrelation. Therefore, we arrange our model as following:

$U_{t-2}, G D P_{t-1}, I N D R O_{t-1}, C P I_{t-1}$, and $P I_{t-1}$ are known as lagged values of $\mathrm{U}, \mathrm{GDP}$, INDRO, CPI, and PI. $\mathrm{U}$ is lagged by two periods and the other values are lagged by one period. Our estimates are that the level of GDP is linearly related to the unemployment rate. We think that this hypothesis could be realistic, because an increase in GDP should cause an unemployment rate. Thus, GDP has a negative effect on unemployment rate - we obtain that $B_{2}$ should be negative. Our linear model might show that if unemployment rate goes up by $1 \%$, the change in GDP would be negative. We performed the steps below in order to find the best model.

\section{1) Log to linear model}

Since we can’t do a direct comparison of the $\mathrm{R}^{\wedge} 2$ measures because our dependent variables are different (unrate and lunrate), we have to convert linear to $\log$ (Figure $2 \& 3$ ). 
However, there is a general methodology to be able to compare the coefficients between these two different regression equations. Now, we can compare the two regression equations. We see that the $\mathrm{R}^{\wedge} 2$ of the $\log$ model is equal to 0.5479 and that it is bigger than the $\mathrm{R}^{\wedge} 2$ of the linear model that is equal to 0.4606 . Therefore, we choose to work with the log model. The log model is a better fit for our data than the linear model (Figure $4 \& 5$ ).

\section{2) Dummy variables}

In general, dummy variables are a flexible tool that can handle a variety of interesting problems. Many economic time series based on monthly or quarterly data exhibit seasonal patterns. In our model, we added a trend variable "time" and a dummy variable "D1" to deseasonalize our economic times series from 1967 to 2016. Our dummy variable has the value of 0 when America has not been in a recession and the value 1 when the country has been in a recession. We tested if adding the time and the dummy variable improved the explanatory power of our model or not. The result was that both improved the explanatory power of our model (Figure 6).

\section{3) Multicollinearity}

Variance inflation factors (VIF) measure how much the variance of the estimated regression coefficients are inflated as compared to when the predictor variables are not linearly related. We decided that knowing VIF will help us to describe how much multicollinearity, which is the correlation between predictors, exists in a regression analysis. Multicollinearity could be a big problem because it can increase the variance of the regression coefficients, making them unstable and difficult to interpret. VIF can be interpret by using the following guidance: If VIF $=1$, we can say that our variables are not correlated $;<\mathrm{VIF}<5$, variables are moderately correlated; $\mathrm{VIF}>5$ to 10 , variables are highly correlated. Since our VIF $=934.41$, we can say that variables are highly correlated, that is we assume that the regression coefficients are poorly estimated due to multicollinearity (Figure 7).Welooked at the levels of the VIF of each independent variable in order to determine if a variable should be eliminated from our regression model since we discovered that we do have multicollinearity.

\section{4) Test for Autocorrelation: Breusch-Pagan Test}

Finally, we test our model for autocorrelation. Autocorrelation is defined as "correlation between members of series of observations ordered in time or space" (Gujarati and Porter, 2009). In order to calculate the Breusch-Pagan test we have to remember the following assumptions:

$$
\begin{aligned}
& y_{t}=\beta_{1}+\beta_{2} x_{t}+u_{t} \quad \text { for } \mathrm{t}=1, \ldots, \mathrm{T} \\
& u_{t}=\rho_{1} u_{t-1}+\rho_{2} u_{t-2}+\ldots+\rho_{p} u_{t-p}+\varepsilon_{t} \quad|\rho|<1
\end{aligned}
$$

where:

$$
\begin{aligned}
& H_{0}: \rho_{1}=\rho_{2}=\ldots=\rho_{p}=0 \\
& H_{1}: \rho_{1} \neq 0 \text { or } \rho_{2} \neq 0 \text { or. } \ldots \text { or } \rho_{p} \neq 0
\end{aligned}
$$

In STATA we have to follow steps below:

1) Estimate the OLS model and obtain the residuals by using the command: "predict res, resid"

2) Generate several variables for lagged values of the residuals by using the following commands (Figure 8).

3) Now we want to calculate the optimal number of lags. In order to do this, we choose to start with a high number of legs (res7), because our number of observations $(n=200)$ is really big. The researcher can decide this on his own. We run the regression and if the $t$ value for the last lag is not significant at $95 \%$, we eliminate the last lag. Then we run the regression again and continue this procedure until one of the lags is significant.

In our model, we needed to run four regressions until the $t$ in the fifth regression was significant (Figure 9). Now we compute the test statistic $(\mathrm{T}-\mathrm{p}) \mathrm{R}^{2}$. Under the null hypothesis this statistic has a $\chi^{2}$ distribution with $\mathrm{p}$ degrees of freedom. $\mathrm{P}$ is the number of lags in our AR process for the error term, which equals 3 . Then we check the value of the statistic we obtained with the Chi-square distribution. In STATA, we first use command "tsset time" to tell STATA which variable is our time variable. Afterwards, we use the command "estatbgodfrey, lags (1/3)" and get the following resultsin figure 10. Now, we have two approaches to check if autocorrelation is present. First, we compare the value of the statistic we obtained with the Chi-square distribution. Our $p$ is 3 and we obtain a $\chi^{2}$ statistic of 188.150 with 3 degrees of freedom and a p-value of 0.00.The $\chi^{2}$ distribution equals 7.81473 which means that it is not bigger than our $\chi^{2}$ value. Second, our p-value is 0.00 and therefore it is less than our alpha of 0.05 . Both approaches show the same result: We reject the null hypothesis that there is no autocorrelation. According to these two approaches we see, that there is autocorrelation present in our model. To solve the problem of autocorrelation, we use the ARIMA regression (Figure 11). We see, that the GDP has a negative effect on the unemployment rate. If GDP goes up, the unemployment rate goes down. 
If the industrial production index increases, the unemployment rate goes down - that is exactly what we expected. CPI seems to have no effect on the unemployment rate. If our PI increases, our unemployment rate slightly decreases.

\section{Conclusion}

In our analysis, we explore a number of possible explanations to proof that our main hypothesis, that is that the decreasing GDP rate should lead to an increasing unemployment rate, was correct. From the data obtained from multiple sources, we can see that weak labor market performance of the United Stated did have a big influence on the GDP and unemployment rate. We started by reviewing papers that shared same thoughts and goals as we did and we compared our results to the literature that we found that was directly related to our paper. In Richard Carter's paper " $A$ Multiple Regression Analysis Fiscal Strategies and Unemployment Rates" (2014) performed test for the multicollinearity was different from our results, but he followed the same steps as we did in our paper to understand the relationship between the variables. As in "Effects of debt and GDP on the unemployment rate: an empirical study" (2015) by Morsheda Hassan and Raja Nassar we also used time series methodology and our result is matching conclusion of their paper, as in both a negative significant correlation between GDP and unemployment rate was discovered. We compared our results of Breusch-Godfrey test to the results from Barbara Sawtelle paper "Analyzing the link between real GDP and employment: An industry sector approach"(2007) and our results were similar.

We started by explaining unemployment rate by GDP, INDRO, CPI, and personal income in the U.S. in the last 50 years. We created and ran our regression assuming that GDP will have a negative effect on unemployment rate. We then asked us whether a linear or a log model would represent a better solution for our model. Then we did a log-linear model transformation in order to compare our R2 values. We determined that the log model was better because of a higher R2 and so we chose to proceed with it. Then we added the dummy variable and the time variable and tested if the additions improved our model. The result was that they improved our model. We then tested for Multicollinearity and Autocorrelation. All of this was done to proof that our model was correct and minimizes errors in order to obtain the best possible result. After we noticed that autocorrelation is present in our model, we used the ARIMA regression to solve this problem. The results were exactly what we expected them to be, namely that GDP has a negative effect on the unemployment rate. In addition, Our R2 of 0.61 and the fact that our $t$ values are significant indicate that there is a strong negative correlation between our dependent variable, unemployment rate and our independent variable GDP.

Figures

Figure 1

\begin{tabular}{|c|c|c|c|c|c|}
\hline Variable & obs & Mean & Std. Dev. & Min & $\operatorname{Max}$ \\
\hline unrate & 200 & 6.1825 & 1.623955 & 3.4 & 10.7 \\
\hline$g d p$ & 200 & 68.43061 & 27.04823 & 29.995 & 116.543 \\
\hline indpro & 200 & 71.53785 & 23.15936 & 35.9409 & 106.5182 \\
\hline$c p i$ & 200 & 134.9446 & 65.83938 & 33 & 242.821 \\
\hline $\mathrm{pi}$ & 200 & 6285.451 & 4624.929 & 650.6 & 16111.1 \\
\hline
\end{tabular}

Figure 2 (linear)

\begin{tabular}{|c|c|c|c|c|c|c|c|}
\hline Source & SS & & $d f$ & MS & \multirow{3}{*}{\multicolumn{2}{|c|}{$\begin{array}{l}\text { Number of obs } \\
\mathrm{F}(4,195) \\
\text { Prob > F } \\
\text { R-squared }\end{array}$}} & \multirow{4}{*}{$\begin{array}{r}200 \\
43.45 \\
0.0000 \\
0.4712 \\
0.4604 \\
1.1929\end{array}$} \\
\hline Model & 247.310505 & & 4 & 61.8276263 & & & \\
\hline Residual & 277.498237 & & 195 & 1.42306788 & & & \\
\hline Total & 524.808742 & & 199 & 2.63722986 & \multicolumn{2}{|c|}{$\begin{array}{l}\text { R-squared } \\
\text { Adj R-squared } \\
\text { Root MSE }\end{array}$} & \\
\hline unrate & Coef. & std. & Err. & $\mathrm{t}$ & $P>|t|$ & [95\% Conf. & Interval] \\
\hline cpi & .0693998 & .009 & 3716 & 7.41 & 0.000 & .050917 & .0878826 \\
\hline gdp & .0620753 & .081 & 2461 & 0.76 & 0.446 & -.0981586 & .2223092 \\
\hline indpro & -.222734 & .040 & 2152 & -5.54 & 0.000 & -.3020466 & -.1434214 \\
\hline pi & -.0002352 & .000 & 2261 & -1.04 & 0.300 & -.000681 & .0002107 \\
\hline _cons & 9.981555 & .96 & 3379 & 10.36 & 0.000 & 8.081575 & 11.88153 \\
\hline
\end{tabular}

Figure $3(\log )$ 
- reg Lunrate Lcpi Lgdp Lindpro Lpi

\begin{tabular}{|c|c|c|c|c|c|c|}
\hline Source & SS & $d f$ & MS & Number of obs & $=$ & 200 \\
\hline Mode $\mathrm{l}$ & 7.90307338 & 4 & 1.97576834 & Prob $>F$ & $=$ & 0.0000 \\
\hline Residual & 5.57218656 & 195 & .028575316 & R-squared & $=$ & 0.5865 \\
\hline Total & 13.4752599 & 199 & .067714874 & $\begin{array}{l}\text { Adj R-squared } \\
\text { Root MSE }\end{array}$ & $\begin{array}{l}= \\
=\end{array}$ & $\begin{array}{l}0.5780 \\
.16904\end{array}$ \\
\hline
\end{tabular}

\begin{tabular}{|c|c|c|c|c|c|c|}
\hline lunrate & Coef. & Std. Err. & $\mathrm{t}$ & $P>|t|$ & [95\% Conf. & Interval] \\
\hline lcpi & -2.685106 & .584259 & -4.60 & 0.000 & -3.837384 & -1.532828 \\
\hline lgdp & -2.804378 & .7178002 & -3.91 & 0.000 & -4.220026 & -1.38873 \\
\hline lindpro & -2.233704 & .3112263 & -7.18 & 0.000 & -2.847506 & -1.619902 \\
\hline Ipi & 3.759593 & .6176775 & 6.09 & 0.000 & 2.541407 & 4.977779 \\
\hline _cons & 4.061465 & .3238649 & 12.54 & 0.000 & 3.422737 & 4.700193 \\
\hline
\end{tabular}

Figure 4 (log model)

- reg unrate yhat2exp

\begin{tabular}{|c|c|c|c|c|c|c|}
\hline Source & SS & $d f$ & MS & Number of obs & $=$ & 200 \\
\hline Model & 287.549324 & 1 & 287.549324 & Prob $>F$ & $=$ & 0.0000 \\
\hline Residual & 237.259418 & 198 & 1.19827989 & R-squared & $=$ & 0.5479 \\
\hline & & & & Adj R-squared & $=$ & 0.5456 \\
\hline
\end{tabular}

\begin{tabular}{r|rrrrrr}
\hline unrate & Coef. & Std. Err. & $t$ & $\mathrm{P}>|\mathrm{t}|$ & [95\% Conf. Interval] \\
\hline yhat2exp & .9843142 & .0635414 & $\mathbf{1 5 . 4 9}$ & $\mathbf{0 . 0 0 0}$ & $\mathbf{. 8 5 9 0 0 9 4}$ & $\mathbf{1 . 1 0 9 6 1 9}$ \\
_cons & .1809013 & .3950837 & 0.46 & $\mathbf{0 . 6 4 8}$ & -.5982106 & .9600132 \\
\hline
\end{tabular}

Figure 5 (linear model)

. reg Lunrate Lyhat1

\begin{tabular}{|c|c|c|c|c|c|c|c|c|}
\hline Source & SS & & $d f$ & MS & \multirow{2}{*}{\multicolumn{3}{|c|}{$\begin{array}{l}\text { Number of obs } \\
F(1,198) \\
\text { Prob }>F\end{array}$}} & \multirow{2}{*}{$\begin{array}{r}200 \\
169.11 \\
0.0000\end{array}$} \\
\hline Model & 6.20736835 & & 1 & 6.20736835 & & & & \\
\hline Residual & 7.26789158 & & 198 & .036706523 & \multicolumn{3}{|c|}{ R-squared } & 0.4606 \\
\hline Total & 13.4752599 & & 199 & .067714874 & Root & MSE & & $\begin{array}{r}0.4579 \\
.19159\end{array}$ \\
\hline lunrate & Coef. & Std. & Err. & $\mathrm{t}$ & $P>|t|$ & {$[95 \%$} & Conf & . Interval] \\
\hline lyhat1 & .950088 & .073 & 0603 & 13.00 & 0.000 & .8060 & 0117 & 1.094164 \\
\hline cons & .0732436 & .132 & 5611 & 0.55 & 0.581 & -.1881 & 1693 & .3346565 \\
\hline
\end{tabular}

Figure 6

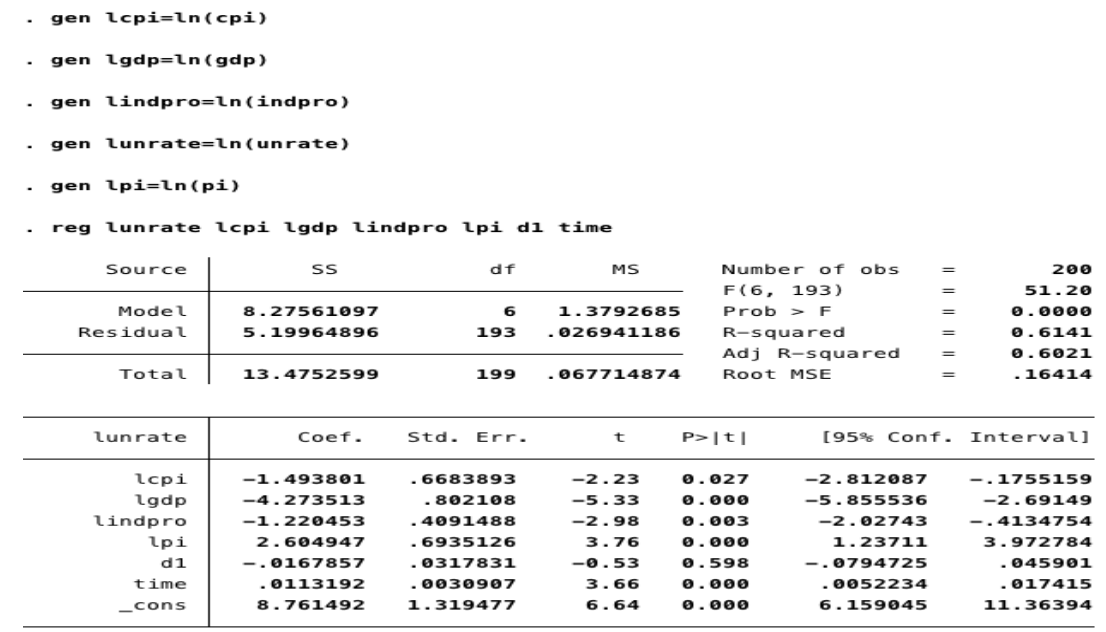


Figure 7

\begin{tabular}{|r|rr} 
vif & & \\
Variable & VIF & $1 /$ VIF \\
\hline lpi & 3185.04 & 0.000314 \\
lcpi & 1211.73 & 0.000825 \\
lgdp & $\mathbf{8 2 9 . 8 8}$ & 0.001205 \\
time & 236.36 & 0.004231 \\
lindpro & 142.42 & 0.007022 \\
d1 & 1.06 & 0.945080 \\
\hline Mean VIF & 934.41 & \\
& &
\end{tabular}

Figure 8

- gen res1=res[_n-1]

(1 missing value generated)

- gen res2=res[_n-2]

( 2 missing values generated)

- gen res3=res[_n-3]

( 3 missing values generated)

- gen res4=res[_n-4]

(4 missing values generated)

- gen res5=res [_n-5]

(5 missing values generated)

- gen res6=res[_n-6]

( 6 missing values generated)

Figure 9

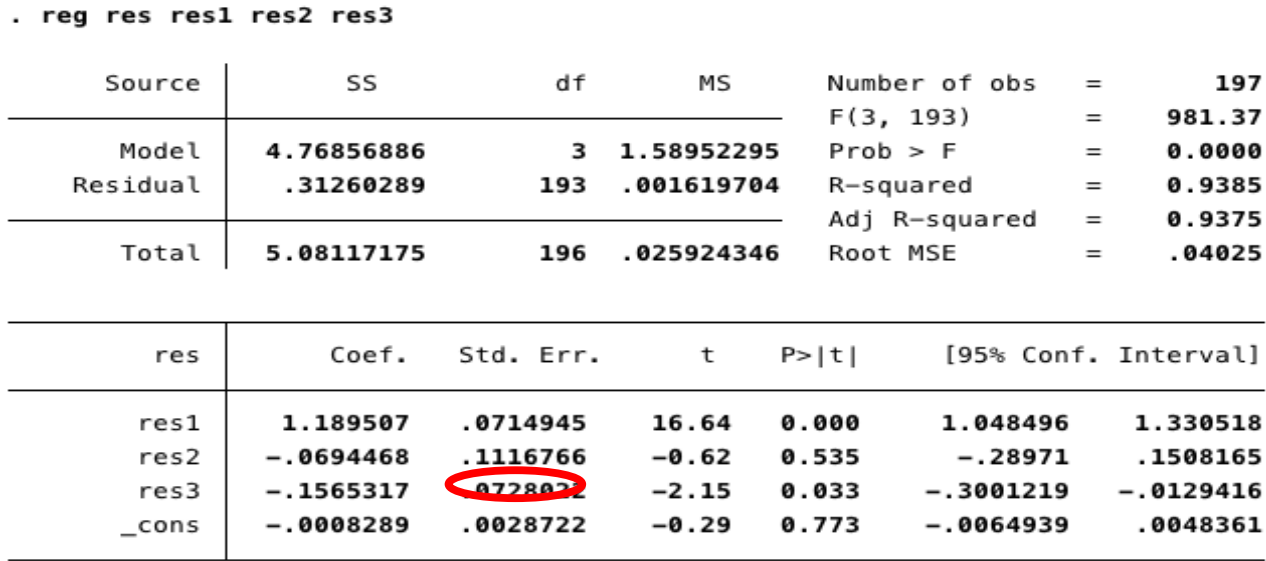


Figure 10

\begin{tabular}{|c|c|c|c|}
\hline lags $(p)$ & chil & $d f$ & Prob $>$ chiz \\
\hline 1 & 187.777 & 1 & 0.0000 \\
\hline 2 & 188.061 & 2 & 0.0000 \\
\hline 3 & 188.150 & 3 & 0.0000 \\
\hline
\end{tabular}

HO: no serial correlation

Figure 11

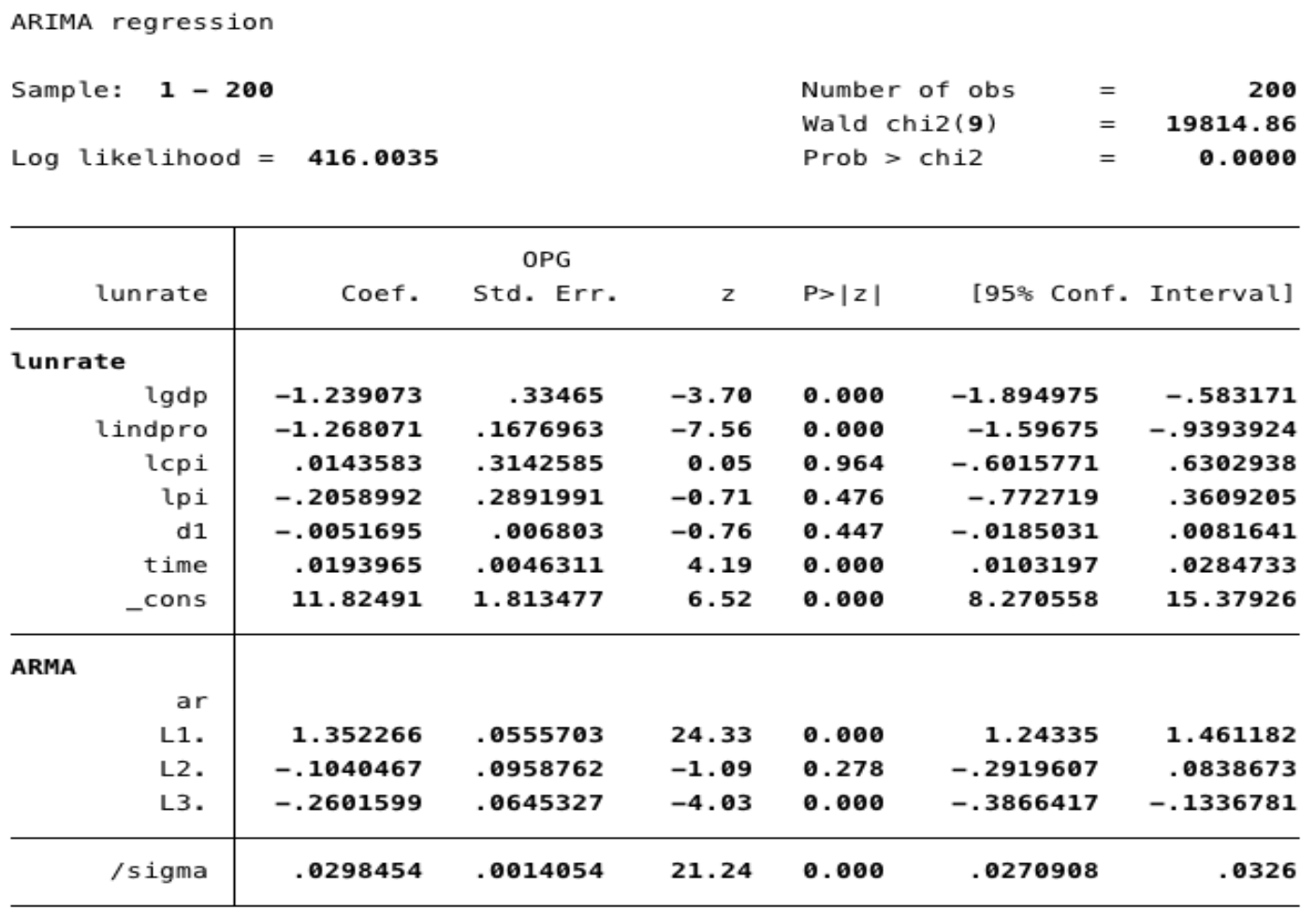

Note: The test of the variance against zero is one sided, and the two-sided confidence interval is truncated at zero.

\section{References}

Bureau of Economic Analysis: US Department of Commerce, 2017

Carter, R. (2014). A Multiple Regression Analysis: Fiscal Strategies and Unemployment Rates. Global Education Journal, Vol. 2014, Issue 2, p79-143. 65p.

Gujarati, D.N. and Porter, D.C. (2009).Basic Econometrics, Fifth Edition

Hoffmann, F. andLemieus, T. (2015). Unemployment in the Great Recession: A Comparison of Germany, Canada, and the United States. Journal of Labor Economics, Vol. 34, (Supplement1), pS95-S139. 44p.

Morsheda, H. and Nassar, R. (2015).Effects of debt and GDP on the unemployment rate: an empirical study. Journal of International Business Disciplines, Vol. 10 Issue 2, p52-69. 18p.

National Bureau of Economic Research, Inc. US Business Cycle Expansions and Contractions, 2010

Sawtelle, B. (2007). Analyzing the link between real GDP and employment: An industry sector approach. Business Economics, Vol. 42, Issue 4, p46-54

Voitovich, S. (2011).Economic development and the level of unemployment in the conditions of economic recession. Economics And Management, 16, p459-464 